\title{
INFLUENCE OF PARTITIONING METHODS ON COMPUTATIONAL COST OF CFD SIMULATIONS APPLIED TO HYDROCYCLONES
}

\section{INFLUENCIA EN EL COSTO COMPUTACIONAL DE LOS MÉTODOS DE FRACCIONAMIENTO EMPLEADOS EN CFD PARA LA SIMULACIÓN DE HIDROCICLONES}

\author{
F.O. COSTA ${ }^{1}$, F.L.B. MATEUS ${ }^{1}$ and I.J. PETRI ${ }^{1 *}$ \\ ${ }^{1}$ Federal University of Lavras, Department of Engineering, Lavras, Minas Gerais, Brazil \\ ${ }^{*}$ Corresponding author. Federal University of Lavras, Department of Engineering, Lavras, Minas Gerais, Brazil, Phone: +5535998310889 \\ e-mail address: irineupetri@gmail.com (I.J. PETRI).
}

\begin{tabular}{|c|}
\hline A R T I C LE I N F O \\
\hline $\begin{array}{l}\text { Article history: } \\
\text { Received 2020-06-21 } \\
\text { Accepted 2020-10-20 } \\
\text { Available online 2020-10-20 }\end{array}$ \\
\hline $\begin{array}{l}\frac{k e y w o r d s}{\text { Partition }} \\
\text { Hydrocyclone } \\
\text { CFD } \\
\text { Parallel simulation }\end{array}$ \\
\hline $\begin{array}{l}\text { palabras - clave } \\
\text { Fraccionamiento } \\
\text { Hidrociclón } \\
\text { CFD } \\
\text { Simulación en paralelo }\end{array}$ \\
\hline
\end{tabular}

\begin{abstract}
A B S T R A C T
In simulations, when using multipartitioned computers, the way in which the mesh is partitioned directly affects the average time per iteration, and therefore, the computational cost. This study proposes an analysis of the average time per iteration of 23 different partition methods available for tridimensional mesh in software FLUENT 19.2. For the calculation of the average iteration time, 100 iterations were used. Generally, the best partitioning methods were those in which the mesh division was made perpendicularly to the axis of the equipment. It was stated the choice of an adequate partitioning method can save high costs of computational power. For the hydrocyclone studied, with a computer with 8 cores, approximately 24.56 hours of simulation were saved, representing almost $20 \%$ of the total time.

R E S U M E N

En simulaciones con computadoras multi-particionadas, la forma con que la malla es fraccionada afecta el tiempo promedio por iteración y el costo computacional. En este trabajo, se analiza el tiempo promedio por iteración de los 23 métodos de fraccionamiento disponibles para mallas tridimensionales del software FLUENT 19.2. Se realizaron 100 iteraciones para la determinación del tiempo promedio por iteración. En general, los mejores métodos de fraccionamiento fueron aquellos en donde la división de la malla fue hecha perpendicularmente al eje en el cual el equipo se encontraba direccionado. En la simulación de un hidrociclón, mediante el uso de una computadora de 8 núcleos, se logró ahorrar aproximadamente 24.56 horas, lo que significó casi el 20\% del tiempo total. De esta manera, la adecuada selección fraccionamiento, puede constituir un gran ahorro del costo computacional.
\end{abstract}




\section{INTRODUCTION}

The hydrocyclones belong to an important group of equipment, designed to make solid-liquid and liquid-liquid separations through the use of centrifugal force. They were invented to address separation problems involving fluids and/or immiscible solids with different densities and compositions (RAPOSO, 2008)

Before the hydrocyclones, the gravitational separators were used. However, the equipment has an efficiency ten to hundreds of times lower than the obtained from hydrocyclones. The hydrocyclones were patented for the first time in 1891 by Bretney (CHINÉ \& CONCHA, 2000) for the solid-liquid separation in the mining industry, and since then it has become a great unitary success.

CFD utilizes numerical methods to solve the conservation equations. The numerical method implementation can be divided into three phases: pre-processing, processing and pos-processing. In pre-processing, the geometrical domain is defined, and subsequently discretized, making up the mesh. The most utilized software for creating the geometry are SpaceClaim $^{\circledR}$, DesignModeler ${ }^{\circledR}$, Gambit $^{\circledR}$, SolidWorks $^{\circledR}$, etc. and for the mesh creation, the most utilized software are ICEM ${ }^{\circledR}$, Meshing ${ }^{\circledR}$ e Gambit ${ }^{\circledR}$. In this phase, physical properties of the fluid are defined along with other parameters (boundary and initial conditions) needed to obtain the solution (LIMA, 2005).

In the processing phase, a solver is used to implement the numerical method in order to obtain the relevant variables (velocity, pressure, temperature). The most utilized commercial software for processing simulations are FLUENT ${ }^{\circledR}$ and $\mathrm{CFX}^{\circledR}$, both pertaining to ANSYS. In the pos-processing phase, the results are analyzed and compared to experimental results in order to validate the numeric method (LIMA, 2005)

In simulations using multipartitioned computers, the way in which the mesh will be divided will influence the time consumed by the simulation. Therefore, this parameter has great influence on the computational cost of the process. The software FLUENT® has twenty three partitioning methods available for tridimensional meshes: Cartesian Axes, Cartesian Strip, Cartesian X-Coordinate, Cartesian Y-Coordinate, Cartesian ZCoordinate, Cartesian R Axes, Cartesian RX-Coordinate, Cartesian RY-Coordinate, Cartesian RZ-Coordinate, Cylindrical Axes, Cylindrical R-Coordinate, Cylindrical ThetaCoordinate, Cylindrical Z-Coordinate, Metis, Principal Axes, Principal Strip, Principal X-Coordinate, Principal YCoordinate, Principal Z-Coordinate, Spherical Axes, Spherical Rho-Coordinate, Spherical Theta-Coordinate and Spherical PhiCoordinate (ANSYS, 2018).

All the partitioning methods have coinciding characteristics between them, such as, keeping approximately the same cell number for each partition, minimizing the number of interfaces between partitions, that is, lowering the superficial limit area of the partition, and minimizing the number of adjacent partitions for each partition. Each partitioning method adapts itself to the geometry of the equipment, and through these principles, the partitions are shaped. The number of partitions is related to the number of cores of the multipartitioned computer. However, the way in which the mesh is divided depends on the geometry of the equipment and the applied method (ANSYS, 2018).

The main objective of each partition having approximately the same numbers of cells is to avoid overburdening the processors, so their load is levelled and they communicate with each other with the same velocity. The communication between the partitions is a slow process, thus the partitions are also created with the smaller superficial area possible in order to minimize the information transmission process between the partitions. To minimize the numbers of adjacent partitions is to reduce the chances of network and routing restraints, accelerating the simulation process (ANSYS, 2018).

The software FLUENT ${ }^{\circledR}$ utilizes either the bisection or the Metis algorithm for the creation of the partitions. Their main advantage is not having a limit for the number of partitions created, and thus, the number of created partitions is essentially the core number of the computer. The functioning principle of the bisection method consists of the purely geometric division of the main domain into subdomains. The domain division for the Metis algorithm, on the other hand, is made through graphic partitioning techniques, which are, most of the times, the most viable (ANSYS, 2018).

Therefore, the objective of this work is to study the twenty-three partitioning methods (for tridimensional geometries) available through the software FLUENT ${ }^{\circledR}$ ANSYS, in order to minimize the simulation time of parallel processing simulations through multipartitioned computers. It is worth noting that some methods, depending on the characteristics of the geometry, produce the same partitioning of the mesh, being, therefore, repeated. The specific objectives of this work are to quantify the average time per iteration along with its standard deviation for all the methods mentioned, to select the most effective partitioning methods for the hydrocyclone, and to analyze the results qualitatively, so that the analysis can also be applied to other equipment.

\section{METODOLOGY}

Boundary conditions utilized for the simulation are showed in Table 1. Dimensions and geometry of the HC11 hydrocyclone are seen in Figure 1.a, and the computational mesh in Figure 1.b. The elements of the mesh are mostly hexahedral, except for the feed region, where tetrahedral cells were used. Mesh and geometry were manufactured in the GAMBIT $^{\circledR}$ software.

The partitioning methods influence the simulation time directly, and, consequently, the computational cost. The analysis of the partitioning methods offered by the software ANSYS FLUENT® 19.2 was made through a mesh of 222.296 cells.

Hydrocyclone simulations usually consist of 5 seconds of simulation with the Volume Of Fluid (VOF) model disabled, 
therefore there is no generation of air cores, and 2 subsequent seconds with the VOF model enabled, so that air cores are formed. Therefore, measures of the average time per iteration were made in triplicates for the simulation times of $0,1,5$ and 6 seconds. At $0 \mathrm{~s}$, the average time per iteration at the initialization was analyzed. At $1 \mathrm{~s}$, the average time per iteration after the stabilization of the methods was observed. At $5 \mathrm{~s}$, the average time per iteration takes into account the insertion of the VOF model and at $6 \mathrm{~s}$ the already stabilized VOF model.

Table 1 - Models and operating conditions used in Ansys Fluent 19.2.

\section{Models and Operating Conditions}

- Transient flow

- Atmospheric pressure at the output (92800 Pa)

- Volumetric feed flow: $313 \mathrm{~cm}^{3} / \mathrm{s}$

- Pressure discretization method: PRESTO! (Petri et al, 2009)

- Relaxation factors (Petri et al, 2009)

Pressure $=0.3$

Density $=1$

Body Force $=1$

Momentum $=0.1$

- Residual criteria $=10^{-4}$

- Multiphase model (air-core) $=$ Volume of Fluid (VOF)

- Time-step Size $(\mathrm{s})=10^{-6}$ a $10^{-5}$
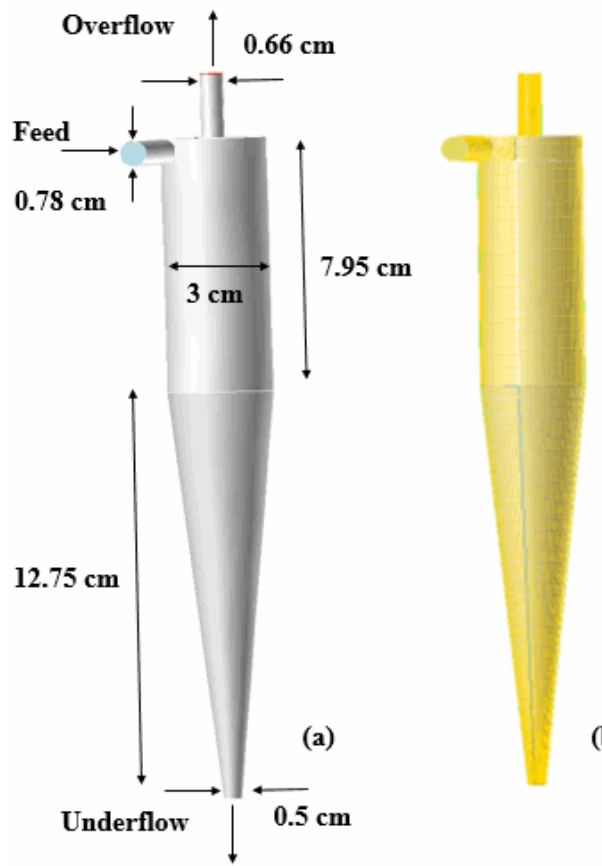

Figure 1 - (a) Geometry, dimensions and (b) mesh of HC11 hydrocyclone.

The standard deviation represents the oscillations in the processing capacity of the computer. In this study, the computer had 8 cores, consequently, the mesh was divided into 8 subdomains.

The analysis was made using 100 time steps, which represent the numbers of iterations. For the starting time of $0 \mathrm{~s}$, the time step size used was $10^{-6}$, and for the remaining time steps, the time step size was raised to $10^{-5}$.

The higher the time step size, the higher the residuals associated with the simulation due to errors associated with the equation solving. Thus, the time step value can raise the residual to an amount higher than the utilized convergence criteria of $10^{-}$ ${ }^{4}$, causing the solution to diverge.

\section{RESULTS AND DISCUSSIONS}

Table 2 and 3 contains the average time per iteration values with its respective standard deviation for the simulation times of $0 \mathrm{~s}$ and $1 \mathrm{~s}$ (simulation times before the insertion of the VOF model), $5 \mathrm{~s}$ and $6 \mathrm{~s}$, (after the insertion of the VOF model into the simulation), respectively.

Figure 2 includes the representations of the main partitions available for tridimensional geometries by the software FLUENT ${ }^{\circledR}$ 19.2.

Analyzing the simulation time of $0 \mathrm{~s}$, it was observed that with the standard deviation associated with the average time per iteration, the methods from Cartesian Y-Coord. to Cylindrical R-Coord. had almost the same values. This occurs because all the models in that interval make the mesh division perpendicularly to the axis in which the hydrocyclone is positioned, the $\mathrm{Y}$ axis.

Table 2 - Average time per iteration for the simulation time of 0.0 and 1.0 seconds (without VOF models).

Simulation time

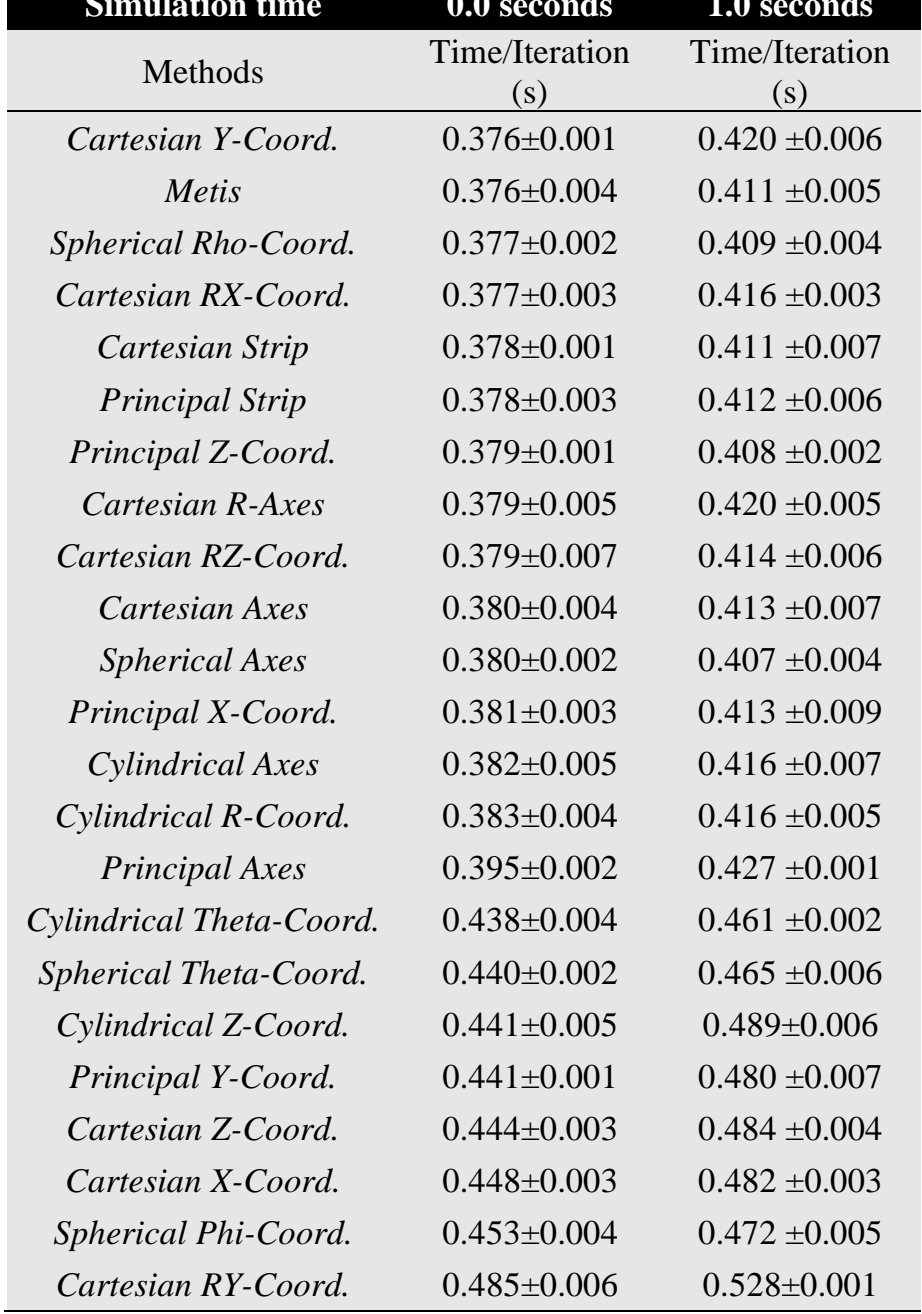


Table 3 - Average time per iteration for the simulation time

\begin{tabular}{ccc} 
of 5.0 and 6.0 seconds (with & VOF models). & \\
\hline Simulation time & $\mathbf{5 . 0}$ seconds & $\mathbf{6 . 0}$ seconds \\
\hline Methods & $\begin{array}{c}\text { Time/Iteration } \\
\text { (s) }\end{array}$ & $\begin{array}{c}\text { Time/Iteration } \\
\text { (s) }\end{array}$ \\
\hline Spherical Rho-Coord. & $0.403 \pm 0.001$ & $0.407 \pm 0.003$ \\
Spherical Axes & $0.408 \pm 0.006$ & $0.413 \pm 0.002$ \\
Principal Z-Coord. & $0.409 \pm 0.004$ & $0.411 \pm 0.004$ \\
Cartesian $R Z$-Coord. & $0.409 \pm 0.001$ & $0.413 \pm 0.003$ \\
Principal Strip & $0.410 \pm 0.005$ & $0.408 \pm 0.008$ \\
Cartesian Axes & $0.411 \pm 0.002$ & $0.406 \pm 0.002$ \\
Cartesian R-Axes & $0.411 \pm 0.004$ & $0.411 \pm 0.002$ \\
Cartesian $Y$-Coord. & $0.411 \pm 0.003$ & $0.415 \pm 0.002$ \\
Cartesian Strip & $0.412 \pm 0.004$ & $0.407 \pm 0.004$ \\
Cartesian RX-Coord. & $0.412 \pm 0.004$ & $0.413 \pm 0.005$ \\
Cylindrical Axes & $0.413 \pm 0.005$ & $0.413 \pm 0.002$ \\
Cylindrical R-Coord. & $0.413 \pm 0.008$ & $0.415 \pm 0.003$ \\
Metis & $0.414 \pm 0.002$ & $0.414 \pm 0.003$ \\
Principal X-Coord. & $0.415 \pm 0.006$ & $0.418 \pm 0.001$ \\
Principal Axes & $0.425 \pm 0.003$ & $0.427 \pm 0.005$ \\
Spherical Theta-Coord. & $0.464 \pm 0.009$ & $0.465 \pm 0.001$ \\
Spherical Phi-Coord. & $0.464 \pm 0.003$ & $0.472 \pm 0.006$ \\
Cylindrical Theta-Coord. & $0.469 \pm 0.007$ & $0.472 \pm 0.002$ \\
Cartesian X-Coord. & $0.483 \pm 0.003$ & $0.483 \pm 0.005$ \\
Principal Y-Coord. & $0.484 \pm 0.003$ & $0.486 \pm 0.001$ \\
Cylindrical Z-Coord. & $0.484 \pm 0.004$ & $0.485 \pm 0.003$ \\
Cartesian Z-Coord. & $0.484 \pm 0.004$ & $0.482 \pm 0.004$ \\
Cartesian RY-Coord. & $0.528 \pm 0.005$ & $0.530 \pm 0.003$ \\
\hline & & \\
\hline
\end{tabular}

Further reason of such result is due to the simulation time of $0 \mathrm{~s}$, which implies the fluid has not yet entered the equipment, therefore, the only partition making calculations for continuity and momentum are the ones close to the feed region, while the other partitions are only updating the results.

The other models formed partitions of similar shapes, as they were all shaped perpendicularly to the other axes, the $X$ and $\mathrm{Z}$ axes. The Cartesian RY-Coord, however, shapes its partitions in the shape of coaxial cylinders onto the $\mathrm{Y}$ axis, giving the partitions a more particular shape in contrast to the other models.

Analyzing the simulation times of 1, 5 and $6 \mathrm{~s}$, the same pattern was observed, in which the lower average times per iteration are encountered when the partition is shaped perpendicularly to the axis on which the hydrocyclone is positioned. The higher average times per iteration are obtained when the partitions are shaped perpendicularly to the other axes. The worst method considering all the simulation times studied was the Cartesian RY-Coord, which has a very particular partition shaping method.

There is generally an ascending pattern for the average time per iteration with the increase of the time step, which starts at $10^{-6}$ at the simulation time of $0 \mathrm{~s}$ and increases to $10^{-5}$ for the rest of the iterations.

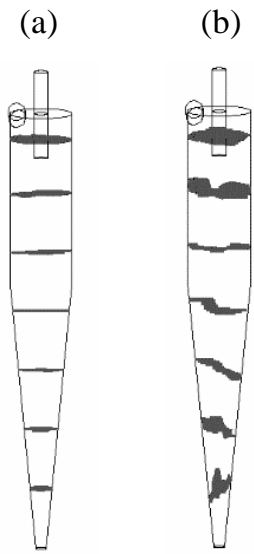

(f)

(g)

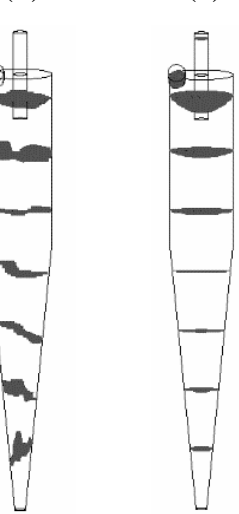

(d)

(e)
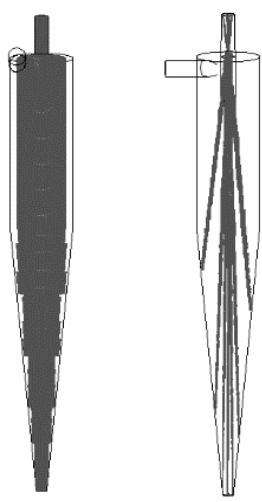

(h)
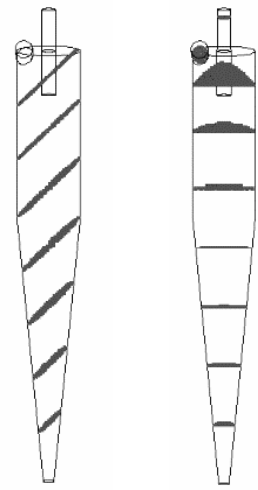

(i)

(j)
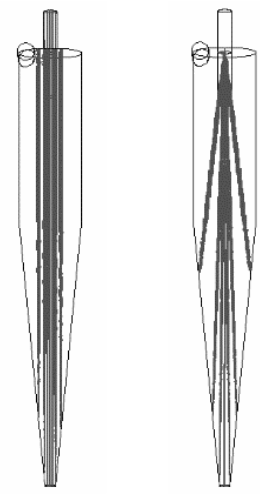

Figure 2 - Main partitioning method types and its different adaptations into the hydrocyclone HC11, (a) Cartesian $Y$ Coord. /Cartesian Strip (b) Metis (c) Spherical Axes/ Spherical Rho-Coord. (d) Principal Z-Coord. / Principal Strip (e) Cartesian R-Axes / Cartesian RX-Coord. (f) Cartesian RY-Coord (g) Spherical Phi-Coord. (h) Cylindrical Z-Coord. (i) Cartesian X-Coord. e (j) Spherical Theta-Coord.

\section{CONCLUSIONS}

Therefore, the study concludes, in a qualitative way, that the better fitted partitions are those in which the mesh is partitioned perpendicularly to the axis in which the equipment is positioned, in the case of the hydrocyclone studied in this work, the $\mathrm{Y}$ axis. On the other hand, the worst partitions were obtained when made perpendicularly to the other axes, in this case, the $\mathrm{X}$ and $\mathrm{Z}$ axes.

More specifically, the study also concludes that the Spherical Axes and Spherical Rho-Coord. were the most efficient methods. While they share the same mesh partition, the first chooses the spherical coordinate in which the interface area of the partitions is minimized, while the second utilizes the spherical coordinate Rho to perform the mesh partition.

The worst method of partition was observed to be the Cartesian RY-Coord., which has a very particular partition shape formed by coaxial cylinders, which maximizes the interfacial area between partitions, significantly raising the average time per iteration.

When comparing only one iteration, the differences in the average time per iteration were small, but when comparing the total time taken to simulate the process, there is the potential 
for a high decrease in computational costs with the optimization of the partitioning method.

For hydrocyclone simulations, of which are needed in average 7,270,000 iterations, utilizing initially a time step of 10 6 that is subsequently raised to $10^{-5}$, the use of the best partitioning method for each simulation time might save up to approximately 24.56 hours of simulation, representing almost $20 \%$ of the total simulation time.

\section{A C K N O W L E D G M E N T}

This work was supported by the, Foundation for Research Support of Minas Gerais (FAPEMIG) project number APQ-00022-18, National Council for Scientific and Technological Development $(\mathrm{CNPq})$ project number 427962/2018-8 and Federal University of Lavras (UFLA) project numbers PIDEG357-2018 and PIDEG76-2018, the authors are grateful to the for their financial support.

\section{R E F E R E N C E S}

ANSYS, Inc. ANSYS Fluent user's guide. Southpointe. Canonsburg, 2013.Available at: $<$ http://www.pmt.usp.br/ACADEMIC/martoran/Notas
ModelosGrad/ANSYS\%20Fluent\%20Users\%20Guide.p df $>$. Accessed on June $22^{\text {st }}, 2020$.

CHINÉ, B.; CONCHA. Flow patterns in conical and cylindrical hydrocyclones. Chemical Engineering Journal, v. 80, n. 1-3, p.267-273, 2000.

LIMA, R. C. Simulação de Grandes Escalas de Escoamentos Incompressíveis com Transferência de Calor e Massa por um Método de Elementos Finitos e Subdomínios. Dissertação (Mestrado em Engenharia Mecânica) Faculdade de Engenharia de Ilha Solteira - UNESP, São Paulo, 2005.

PETRI JUNIOR.; C. R. DUARTE.; L.G. M. VIEIRA. Aplicações das técnicas de CFD para predição da distribuição de vazões volumétricas em hidrociclones dispostos em distintas baterias. Enemp, 2009.

RAPOSO, G. M. Simulação Numérica do Escoamento em Hidrociclone Destinado a Aplicação de Alto Teor de Óleo. Dissertação (Mestrado em Engenharia Mecânica) Pontifícia Universidade Católica do Rio de Janeiro, Rio de Janeiro, RJ, 2008.

VIEIRA, L. G. M. Otimização dos Processos de Separação em Hidrociclones Filtrantes. Tese (Doutorado em Engenharia Química) - Universidade Federal de Uberlândia, Uberlândia, MG, 2006. 